\title{
DIFFERENTIAL TAXATION AND THE EQUILIBRIUM STRUCTURE OF INTEREST RATES
}

\author{
Walter N. TOROUS* \\ The University of Michigan, Ann Arbor, MI 48109, USA \\ Received March 1982, final version received November 1984
}

\begin{abstract}
Equilibrium coupon bond pricing relationships given differential taxation are derived under uncertainty assuming that both corporate and municipal bonds were originally issued at par but are currently selling at a discount. The impact of differential taxation upon the term structure and coupon structure of interest rates is investigated, while the tax structure of interest rates is uniquely characterized. Differential taxation substantially alters the prevailing equilibrium structure of interest rates.
\end{abstract}

\section{Introduction}

Apart from empirical investigations, relatively little effort has been expended on systematically analyzing tax effects on the term structure of interest rates. Robichek and Niebuhr (1970) demonstrated that if quotations on discounted U.S. Treasury bonds are employed, tax induced bias can substantially alter the shape of the estimated yield curve. McCulloch (1975) originated an empirical procedure by which differential tax factors are explicitly taken into account in estimating the term structure and obtained a significantly improved fit to the available data. Subsequently, Schaefer (1981) developed a method of measuring the term structure which specifically accommodates the tax dependence of an investor's choice of securities. The empirical results established that the shape of the term structure may be markedly different for differing tax brackets.

This paper systematically investigates these tax effects given a positive theory of coupon bond valuation within an uncertainty framework. As originally noted by Domar and Musgrave (1944), the imposition of taxation

\footnotetext{
*This paper draws on my Ph.D. dissertation written at the University of Pennsylvania. I would like to thank my dissertation committee, Robert Shiller, chairman, E. Philip Jones, and Beth Allen for many helpful discussions and suggestions. Subsequent drafts of this paper benefited from discussions with Clifford Ball, Stephen Shreve, Adrian Tschoegl, and Hal Varian. Special thanks to an anonymous referee whose comments significantly improved this paper. Sayan Chatterjee provided excellent research assistance. The financial support of the Humanities and Social Sciences Council of Canada is gratefully acknowledged. Any remaining errors are my responsibility.
} 
within such a framework reduces not only the expected return to an investment but also its corresponding risk. We give formal cognizance to the uncertainty which pervades coupon bond markets, and evaluate the consequences of changes in taxation policy upon the equilibrium structure of interest rates. In particular, we consider the coupon structure - the response in yields to alternative coupon levels; the tax structure - the response in yields to alternative levels of taxation; and the term structure - the response in yields to alternative terms to maturity.

Trading in coupon bond markets will be assumed to take place continuously in time, and prevailing uncertainty summarized by state variables which follow diffusion processes. The economy is posited to have reached an underlying equilibrium in which the dynamics of these state variables have been determined. Coupon bonds are then priced relative to these processes so as to eliminate after-tax arbitrage opportunities.

Tax effects within U.S. coupon bond markets arise for a number of reasons. Coupons on municipal debt, as opposed to corporate debt, are exempt from ordinary income taxation. If coupon bonds were originally issued at par but are currently selling at a discount, then realized appreciation is capital gains taxable. Tax authorities treat coupon bonds selling above par asymmetrically. In the case of a corporate bond, the amortizable bond premium is applied both as an adjustment to the basis of the bond, for determining gain or loss, and as a deduction in computing taxable income. On municipals the amortizable bond premium for the taxable year is an adjustment to the basis of the bond only.

In section 2 we develop an equilibrium coupon bond pricing relationship given the differential taxation of realized capital gains versus coupon income and the differential taxation of corporate coupon income versus municipal coupon income. Investors are assumed to belong to a common tax bracket. In order to emphasize these differential tax effects, we investigate the equilibrium pricing of corporate and municipal bonds which were originally issued at par but are currently selling at a discount. ${ }^{1}$ Presently, in U.S. coupon bond markets a majority of bonds sell at a discount from par.

To examine the impact of differential taxation upon the equilibrium structure of interest rates, we subsequently posit a single state variable, the nominal spot rate of interest. We then establish in section 3 that increases (decreases) in the ordinary income tax rate result in increases (decreases) in corporate yields. Municipal yields are independent of the prevailing ordinary income tax rate. Alternatively, increases (decreases) in the capital gains tax

\footnotetext{
${ }^{1}$ We do not consider original issue discount bonds. At their issue these bonds are priced at a discount from par. By contrast, we examine the equilibrium pricing of coupon bonds initially priced at par but subsequently selling at a discount because of currently higher prevailing interest rates. The taxation of these bonds differs from the taxation of original issue discount bonds.
} 
rate give rise to increases (decreases) in both corporate and municipal yields. Additionally, yields are not independent of coupon level. The characterization of this coupon effect is extended within an uncertainty framework.

Differential taxation also biases the yield curve. We illustrate these biases in section 4 assuming nominal spot rate dynamics are now characterized by a trend-adjusted Ornstein-Uhlenbeck process. Under this specification, the current nominal spot rate reverts stochastically to a long-term mean, the fluctuations of the process being independent of the level of the nominal spot rate. This nominal spot rate process is economically intuitive and, furthermore, there exists empirical evidence supporting its validity. Given estimated parameters of the trend-adjusted Ornstein-Uhlenbeck process, differential taxation exerts a downward bias on the short-term end of the corporate yield curve. Furthermore, differential taxation imparts a uniform downward bias across all terms to maturity of the municipal yield curve. However, if municipals are selling at a sufficiently deep discount this latter effect may be augmented by a tax induced upward bias at the municipal yield curve's short-term end. Section 5 summarizes our conclusions.

\section{Tax-adjusted equilibrium pricing of coupon bonds}

A coupon bond may be characterized as a portfolio of pure discount bonds. The principal payment of each pure discount bond corresponds to a contractually stipulated coupon payment. Given a continuous-time framework, the equilibrium price of a default-free coupon bond may then be expressed as a weighted integral of equilibrium default-free pure discount bond prices.

We assume that there exists a set of $n$ state variables $\underline{Y}=\left\{Y_{1}, \ldots, Y_{n}\right\}$ whose current values specify all relevant information for investors. The state variables are assumed to be jointly Markov, with dynamics of the ith state variable described by the stochastic differential equation

$$
\mathrm{d} Y_{i}(t)=a_{i}(\underline{Y}, t) \mathrm{d} t+\underline{\sigma}_{i}(\underline{Y}, t) \mathrm{d} \underline{Z}(t), \quad i=1, \ldots, n,
$$

where $\underline{Z}=\left\{Z_{1}, Z_{2}, \ldots, Z_{k}\right\}$ is a $k$-dimensional standardized Wiener process with $n \geqq k .^{2}$ Here $a_{i}(\underline{Y}, t)$ represents the expected rate of change in the $i$ th state variable, while $\underline{\sigma}_{i}(\underline{Y}, t)$ is a $k$-dimensional vector of diffusion coefficients measuring the response of the ith state variable to each of the economy's sources of uncertainty. The current state of the economy, and therefore the prevailing structure of interest rates, is summarized by current values of these

\footnotetext{
${ }^{2} \mathrm{~A} k$-dimensional standardized Wiener process is a collection of $k$ independent random variables, each with mean increment zero and unitary variance per unit time increment. We allow $n \geqq k$ since a number of the state variables may be non-stochastic. For example, a state variable may be an average of other state variables.
} 
state variables. The economy is assumed to have reached an underlying equilibrium in which all investors agree upon and take as given the current values of the state variables and their posited dynamics.

Bond markets are competitive with each investor acting like a price taker and, apart from taxation, bond markets are assumed frictionless. Riskless instantaneous borrowing or lending takes place at the exogenously determined equilibrium nominal spot rate of interest $r$. Bond markets are open continuously with trading allowed only at equilibrium prices.

The following tax regime will be assumed throughout. Receipt of corporate coupon income is taxed at the ordinary income tax rate $i \quad(0 \leqq i<1)$, municipal coupon income being exempt. Realizable gains on coupon bonds are subject to capital gains taxation at the capital gains tax rate $g(0 \leqq g<1)$ with $100 \%$ offsets on losses. Instantaneous borrowing or lending at the nominal spot rate of interest is ordinary income taxable. Furthermore, the ordinary income tax rate exceeds the capital gains tax rate, $i>g$, and all investors belong to a common tax bracket.

The assumption of a common tax bracket is empirically implausible. However, as argued by Schaefer (1982), problems arise if this assumption is relaxed. Specifically, in a bond market with differential taxation but which is otherwise frictionless, the existence of multiple tax brackets is inconsistent with bond market equilibrium. When there are investors in more than one tax bracket it is impossible to set prices such that arbitrage opportunities are eliminated for all investors. Our analysis is consistent with bond market equilibrium by assuming all inventors' tax rates are equalized. We cannot obtain exact results as to the equilibrium pricing formulations that will result in a market characterized by investors with different tax brackets.

Within the continuous-time framework, coupons are assumed to be received continuously and ordinary income taxes due on corporate coupon income are assumed paid continuously. Capital gains taxes are also assumed to be paid continuously on instantaneously realizable capital gains. We draw no distinction between short-term and long-term capital gains. This assumption, however, is at variance with the provision of most tax codes requiring that financial assets be held for a minimum period of time, usually one year, before the resultant gains or losses are subject to the lower long-term capital gains tax rate. Consequently, we ignore the value of the timing option on capital gains as noted by Constantinides (1983), and Constantinides and Ingersoll (1982). That is, given a distinction between short-term and longterm capital gains, bond prices should reflect an optimal trading policy on the part of investors which includes, among other things, the realization of short-term capital losses and the deferment of the realization of short-term capital gains. While the assumption that capital gains taxes are paid continuously is restrictive, as previously noted by Ananthanarayanan and Schwartz (1980) it is required within a continuous-time framework to ensure a unique equilibrium bond value. 
We now characterize the equilibrium price of a coupon bond given the continuous-time framework and presumed tax regime. Consider a bond selling at a discount which pays a constant coupon $C, 0<C<1$, continuously between $t$ (today) and $m$ (maturity). $B(\underline{Y}(t), t, m)$ denotes the current price of this default-free coupon bond and, without loss of generality, assume the price is normalized so that at maturity,

$$
B(\underline{Y}(m), m, m)=1 \quad \text { for all } m \in(t, \infty) .
$$

Let $P(\underline{Y}(t), t, \omega)$ denote the current price of a default-free pure discount bond promising an after-tax cash flow of one dollar at time $\omega(t \leqq \omega \leqq m)$. Assuming the availability of these pure discount bonds, we may write

$$
B(\underline{Y}(t), t, m)=\delta^{*} \int_{t}^{m} P(\underline{Y}(t), t, \omega) \mathrm{d} \omega+\delta^{* *} P(\underline{Y}(t), t, m) .
$$

Evaluating expression (3) at $t+h$, where $h>0$, gives

$$
\begin{gathered}
B(\underline{Y}(t+h), t+h, m)=\delta^{*} \int_{t+h}^{m} P(\underline{Y}(t+h), t+h, \omega) \mathrm{d} \omega \\
+\delta^{* *} P(\underline{Y}(t+h), t+h, m), \quad \text { and } \\
{[B(\underline{Y}(t+h), t+h, m)-B(\underline{Y}(t), t, m)] / h} \\
=\delta^{*} \int_{t}^{m}([P(\underline{Y}(t+h), t+h, \omega)-P(\underline{Y}(t), t, \omega)] / h) \mathrm{d} \omega \\
\quad-\delta^{*} \int_{t}^{t+h}(P(\underline{Y}(t+h), t+h, \omega) / h) \mathrm{d} \omega \\
+\delta^{* *}([P(\underline{Y}(t+h), t+h, m)-P(\underline{Y}(t), t, m)] / h) .
\end{gathered}
$$

As $h \rightarrow 0^{+}$we have, ${ }^{3}$

$$
\mathrm{d} B(\underline{Y}(t), t, m)=\delta^{*} \int_{t}^{m} \mathrm{~d} P(\underline{Y}(t), t, \omega) \mathrm{d} \omega+\delta^{* *} \mathrm{~d} P(\underline{Y}(t), t, m)-\delta^{*} \mathrm{~d} t
$$

From expression (4), the appreciation of a default-free coupon bond is dependent upon the appreciation of default-free pure discount bonds. If the appreciation of a default-free coupon bond is capital gains taxable, we

${ }^{3}$ Cauchy's Dominated Convergence Theorem allows us to take the differentiation operator through the integral operator. 
require that the appreciation of default-free pure discount bonds also be capital gains taxable. Intuitively, we may view a pure discount bond as a special case of a coupon bond with zero coupon payments and therefore subject to the same taxation provisions.

Multiplying expression (4) by $(1-g)$ and rearranging gives

$$
\begin{aligned}
& (1-g) \mathrm{d} B(\underline{Y}(t), t, m)+(1-g) \delta^{*} \mathrm{~d} t \\
& \quad=\delta^{*} \int_{t}^{m}(1-g) \mathrm{d} P(\underline{Y}(t), t, \omega) \mathrm{d} \omega+\delta^{* *}(1-g) \mathrm{d} P(\underline{Y}(t), t, m),
\end{aligned}
$$

the right-hand side of expression (5) representing the instantaneous after-tax return to the portfolio of pure discount bonds.

In equilibrium, the instantaneous after-tax return to the coupon bond must equal the instantaneous after-tax return to the posited portfolio of pure discount bonds. However, the instantaneous after-tax return to a fully taxable corporate bond is given by

$$
(1-g) \mathrm{d} B(\underline{Y}(t), t, m)+(1-i) C \mathrm{~d} t \quad \text { for all } m \in(t, \infty),
$$

and from expression (5) we have,

$$
\begin{aligned}
& (1-g) \mathrm{d} B(\underline{Y}(t), t, m)+(1-i) C \mathrm{~d} t \\
& =(1-g) \mathrm{d} B(\underline{Y}(t), t, m)+(1-g) \delta^{*} \mathrm{~d} t \quad \text { for all } m \in(t, \infty),
\end{aligned}
$$

or

$$
\delta^{*}=T C \quad \text { where } \quad T=(1-i) /(1-g) \text { for all } m \in(t, \infty) .
$$

Applying the terminal condition, expression (2), to expression (3) gives ${ }^{4}$

$$
\delta^{* *}=1 \text { for all } m \in(t, \infty) .
$$

${ }^{4} \mathrm{An}$ alternative derivation of the equilibrium value of $\delta^{* *}$ which makes clear its independence with respect to the coupon bond's term to maturity is also possible. The equilibrium value of a coupon bond is

$$
B(\underline{Y}(t), t, m)=\delta^{*} \int_{t}^{m} P(\underline{Y}(t), t, \omega) \mathrm{d} \omega+\delta^{* *} P(\underline{Y}(t), t, m) .
$$

This characterization holds for all maturity dates $m \in(t, \infty)$ and coupon payments. In particular, restricting our attention to the case $C=0$, in the case of a corporate bond we have $\delta^{*}=T \cdot 0=0$, while in the case of a municipal bond we have $\delta^{*}=(1-g)^{-1} \cdot 0=0$, giving $B(\underline{Y}(t), t, m)=$ $\delta^{* *} P(\underline{Y}(t), t, m)$ for all $m \in(t, \infty)$. However, a coupon bond for which $C=0$ is but a pure discount bond, and equilibrium in this case requires $B(\underline{Y}(t), t, m)=P(\underline{Y}(t), t, m)$ for all $m \in(t, \infty)$. Hence, $\delta^{* *}=1$ for all $m \in(t, \infty)$. 
An analogous argument establishes in the case of a tax-exempt municipal bond

$$
\begin{aligned}
(1-g) \mathrm{d} B(\underline{Y}(t), t, m)+C \mathrm{~d} t= & (1-g) \mathrm{d} B(\underline{Y}(t), t, m) \\
& +(1-g) \delta^{*} \mathrm{~d} t \quad \text { for all } m \in(t, \infty),
\end{aligned}
$$

or

$$
\delta^{*}=(1-g)^{-1} C \quad \text { for all } m \in(t, \infty)
$$

We may now characterize equilibrium coupon bond prices assuming investors belong to a common tax bracket and given the assumed tax regime. The equilibrium price of a default-free corporate bond may be expressed as

$$
B_{\mathrm{CP}}(\underline{Y}(t), t, m)=C T \int_{t}^{m} P(\underline{Y}(t), t, \omega) \mathrm{d} \omega+P(\underline{Y}(t), t, m),
$$

while the equilibrium price of a default-free municipal bond becomes

$$
B_{\mathrm{MU}}(\underline{Y}(t), t, m)=C(1-g)^{-1} \int_{t}^{m} P(\underline{Y}(t), t, \omega) \mathrm{d} \omega+P(\underline{Y}(t), t, m) .
$$

Here $P(\underline{Y}(t), t, \omega)$ is the equilibrium price of a pure discount bond maturing at time $\omega(t \leqq \omega \leqq m)$, its instantaneous appreciation assumed capital gains taxable.

\section{The tax structure and coupon structure of interest rates}

Following Merton (1973), Brennan and Schwartz (1977), Vasicek (1977), Dothan (1978), and Ananthanarayanan and Schwartz (1980), we assume a single state variable, the nominal spot rate of interest, $r$, characterizes equilibrium bond prices. ${ }^{5}$ By simplifying the underlying economic framework, we concentrate on examining the effects of taxation upon the resultant equilibrium structure of interest rates. In particular, this section subsequently examines the impact of differential taxation upon equilibrium corporate and municipal yields (the tax structure of interest rates), as well as the relationship between coupon level and equilibrium yields (the coupon structure of interest rates).

The state variable $r$ evolves as a non-standardized Wiener process

$$
\mathrm{d} r=a_{r}(r, t) \mathrm{d} t+\sigma_{r}(r, t) \mathrm{d} Z,
$$

\footnotetext{
${ }^{5}$ We cannot in general derive comparative static results for the more general case where $n$ state variables $\underline{Y}$ characterize equilibrium bond prices. This analysis requires that specific assumptions regarding the taxation of these state variables be made.
} 
where $a_{r}$ and $\sigma_{r}$ denote the instantaneous drift and standard deviation, respectively, of the nominal spot rate process. The equilibrium price of a default-free corporate bond may then be written as

$$
B_{\mathrm{CP}}(r(t), t, m)=C T \int_{t}^{m} P(r(t), t, \omega) \mathrm{d} \omega+P(r(t), t, m),
$$

while the equilibrium price of a default-free municipal bond becomes

$$
B_{\mathrm{MU}}(r(t), t, m)=C(1-g)^{-1} \int_{t}^{m} P(r(t), t, \omega) \mathrm{d} \omega+P(r(t), t, m) .
$$

To complete the specification requires the equilibrium price of a capital gains taxable pure discount bond $P(r(t), t, \omega)(t \leqq \omega \leqq m)$. Given the posited nominal spot rate dynamics, $P(r(t), t, \omega)$ is the unique solution to the second order partial differential equation, ${ }^{6}$

$$
\frac{1}{2} \frac{\partial^{2} P}{\partial r^{2}} \sigma_{r}^{2}+\left(a_{r}-\lambda \sigma_{r}\right) \frac{\partial P}{\partial r}-\operatorname{Tr} P+\frac{\partial P}{\partial t}=0
$$

subject to the boundary condition,

$$
P(r(\omega), \omega, \omega)=1 .
$$

Here the exogenous parameter $\lambda$ denotes the market price of risk, and gives the additional expected pure discount bond rate of return commensurate with bearing an additional unit of risk as measured by the instantaneous standard deviation of the pure discount bond's rate of return. As before, $T=(1-i) /$ $(1-g)$. The unique and general solution to this second order partial differential equation is given by

$$
P(r(t), t, \omega)=\mathrm{E}_{t}\left\{\exp -\int_{t}^{\omega}\left[\operatorname{Tr}(s)+1 / 2 \lambda^{2}(r(s), s)\right] \mathrm{d} s+\int_{t}^{\omega} \lambda(r(s), s) \mathrm{d} Z(s)\right\},
$$

where $\mathrm{E}_{t}$ is the expectation operator conditional upon the state variable at time $t .^{7}$ Therefore, within our partial equilibrium framework, exogenously

\footnotetext{
${ }^{6}$ Assume, without loss of generality, the existence of two capital gains taxable pure discount bonds of distinct maturities. The price of each is posited to be a $C^{2}$ function of the prevailing ordinary income taxable nominal spot rate, $r(t)$, and time, $t$. We may form a riskless hedge in these two pure discount bonds, and the absence of arbitrage opportunities on an after-tax basis requires that the given second order partial differential equation be satisfied. Equilibrium further implies that the market price of risk, $\lambda$, defined here as the ratio of a pure discount bond's expected excess return to the corresponding instantaneous standard deviation, is independent of term to maturity.

${ }^{7}$ See Friedman (1964, especially p. 64).
} 
characterizing both nominal spot rate dynamics and the market price of risk uniquely characterizes the equilibrium price of a pure discount bond and, in turn, the equilibrium prices of default-free corporate and municipal bonds.

Given equilibrium bond prices, equilibrium yields follow. Assuming a default-free corporate bond with term to maturity $\tau=m-t$ and which continuously pays a constant coupon $C$, the corresponding yield-to-maturity $y_{\mathrm{CP}}$ is uniquely determined by the implicit function

$$
B_{\mathrm{CP}}(r(t), t, m)-C y_{\mathrm{CP}}^{-1}-\left(1-C y_{\mathrm{CP}}^{-1}\right) \exp \left(-y_{\mathrm{CP}} \tau\right)=0 .
$$

Alternatively, assuming a default-free municipal bond, the corresponding yield-to-maturity $y_{\mathbf{M U}}$ is uniquely determined by the implicit function

$$
B_{\mathrm{MU}}(r(t), t, m)-C y_{\mathrm{MU}}^{-1}-\left(1-C y_{\mathrm{MU}}^{-1}\right) \exp \left(-y_{\mathrm{MU}} \tau\right)=0 .
$$

Equilibrium yields systematically vary in response to changes in prevailing tax rates. To investigate the change in corporate yields brought about by changes in the ordinary income tax rate, we totally differentiate (8) with respect to $y_{\mathrm{CP}}$ and $i$,

$$
\frac{\partial y_{\mathrm{CP}}}{\partial i}=\frac{\partial B_{\mathrm{CP}} / \partial i}{\left(C / y_{\mathrm{CP}}^{2}\right)\left(\exp \left(-y_{\mathrm{CP}} \tau\right)-1\right)-\tau\left(1-C / y_{\mathrm{CP}}\right) \exp \left(-y_{\mathrm{CP}} \tau\right)} \text {. }
$$

The change in municipal yields due to changes in the ordinary income tax rate is illustrated by totally differentiating (9) with respect to $y_{\mathrm{MU}}$ and $i$,

$$
\frac{\partial y_{\mathrm{MU}}}{\partial i}=\frac{\partial B_{\mathrm{MU}} / \partial i}{\left(C / y_{\mathrm{MU}}^{2}\right)\left(\exp \left(-y_{\mathrm{MU}} \tau\right)-1\right)-\tau\left(1-C / y_{\mathrm{MU}}\right) \exp \left(-y_{\mathrm{MU}} \tau\right)} \text {. }
$$

The denominators of the preceding expressions are unambiguously negative since the coupon bonds are assumed selling at a discount. ${ }^{8}$ It follows that

$$
\operatorname{sgn}\left[\frac{\partial y_{\mathrm{CP}}}{\partial i}\right]=-\operatorname{sgn}\left[\frac{\partial B_{\mathrm{CP}}}{\partial i}\right] \text { and } \operatorname{sgn}\left[\frac{\partial y_{\mathrm{MU}}}{\partial i}\right]=-\operatorname{sgn}\left[\frac{\partial \mathbf{B}_{\mathrm{MU}}}{\partial i}\right]
$$

Ceteris paribus, within our economic framework the nominal spot rate of interest will increase (decrease) in response to an increase (decrease) in the prevailing ordinary income tax rate. Recall that instantaneous borrowing or

${ }^{8}$ For example, consider the denominator of $\partial y_{\mathrm{CP}} / \partial i$. Since $y_{\mathrm{CP}}>0$ it follows that $\exp \left(-y_{\mathrm{CP}} \tau\right)-$ $1<0$ for $\tau=m-t>0$, and as such $\left(C / y_{\mathrm{CP}}^{2}\right)\left(\exp \left(-y_{\mathrm{CP}} \tau\right)-1\right)<0$. Since the coupon bond is assumed selling at a discount from par, then $C<y_{\mathrm{CP}}$ or $1-C / y_{\mathrm{CP}}>0$ giving $\tau\left(1-C / y_{\mathrm{CP}}\right) \exp \left(-y_{\mathrm{CP}} \tau\right)>0$. Taking these results together, we have $\left(C / y_{\mathrm{CP}}^{2}\right)\left(\exp \left(-y_{\mathrm{CP}} \tau\right)-1\right)-\tau\left(1-C / y_{\mathrm{CP}}\right) \exp \left(-y_{\mathrm{CP}} \tau\right)<0$. A completely analogous argument establishes that the denominator of $\partial y_{\mathrm{MU}} / \partial i$ is also unambiguously negative. 
lending at the nominal spot rate of interest is ordinary income taxable and, furthermore, all investors belong to a common tax bracket. In the absence of ordinary income taxation $(i=0)$, equilibrium in the market for instantaneous risk-free loans is characterized by

$$
L_{\mathrm{D}}\left(r_{*}\right)=L_{\mathrm{S}}\left(r_{*}\right) .
$$

Here $L_{\mathrm{D}}$ denotes the demand for instantaneous risk-free loans, $L_{\mathrm{S}}$ denotes the supply of instantaneous risk-free loans, while $r_{*}$ is the nominal spot rate of interest which in the absence of ordinary income taxation equilibrates demand with supply. With the imposition of ordinary income taxation $(i>0)$, equilibrium in this market is now characterized by

$$
L_{\mathrm{D}}((1-i) r)=L_{\mathrm{S}}((1-i) r) \text {, }
$$

where $r$ is the pre-tax nominal spot rate of interest which equilibrates demand with supply. It follows then that, ceteris paribus,

$$
(1-i) r=r_{*} \quad \text { or } \quad r=\frac{1}{(1-i)} r_{*} .
$$

The prevailing nominal spot rate of interest is grossed up by one minus the prevailing ordinary income tax rate. The equilibrium quantity of risk-free loans is unaltered by the imposition of ordinary income taxation since the equilibrium after-tax nominal spot rate of interest is unaltered. Furthermore, the government collects zero tax revenue as a result of a change in the prevailing ordinary income tax rate since all lenders and borrowers belong to a common tax bracket. Ceteris paribus, investors' preferences, endowments, and available production opportunities are unaltered by this particular fiscal policy. Under these assumptions, we may establish that $\partial B_{\mathrm{CP}} / \partial i<0$ and $\partial B_{\mathrm{MU}} / \partial i=0 .{ }^{9}$ It follows that

${ }^{9} \mathrm{~B}_{\mathrm{CP}}(r(t), t, m)=C T \int_{t}^{m} P(r(t), t, \omega) \mathrm{d} \omega+P(r(t), t, m)$, and $B_{\mathrm{MU}}(r(t), t, m)=C(1-g)^{-1} \int_{t}^{m} P(r(t), t, \omega) \mathrm{d} \omega+$ $P(r(t), t, m)$, where under our assumptions,

$$
\begin{aligned}
P(r(t), t, \omega) & =\mathrm{E}_{t} \exp \left\{-\int_{t}^{\infty}\left[\operatorname{Tr}(s)+1 / 2 \lambda^{2}(r(s), s)\right] \mathrm{d} s+\int_{t}^{\infty} \lambda(r(s), s) \mathrm{d} Z(s)\right\}, \\
& =\mathrm{E}_{t} \exp \left\{-\int_{t}^{\infty}\left[(1-g)^{-1} r_{*}(s)+1 / 2 \lambda^{2}\left(r_{*}(s), s\right)\right] \mathrm{d} s+\int_{t}^{\omega} \lambda\left(r_{*}(s), s\right) \mathrm{d} Z(s)\right\},
\end{aligned}
$$

and it follows that $\partial P(r(t), t, \omega) / \partial i=0$. Then,

$$
\begin{aligned}
\frac{\partial B_{\mathrm{CP}}(m)}{\partial i} & =-C(1-g)^{-1} \int_{t}^{m} P(\omega) \mathrm{d} \omega+C T \int_{i}^{m} \frac{\partial P(\omega)}{\partial i} \mathrm{~d} \omega+\frac{\partial P(m)}{\partial i} \\
& =-C(1-g)^{-1} \int_{t}^{m} P(\omega) \mathrm{d} \omega<0, \text { while } \\
\frac{\partial B_{\mathrm{MU}}(m)}{\partial i} & =C(1-g)^{-1} \int_{t}^{m} \frac{\partial P(\omega)}{\partial i}+\frac{\partial P(m)}{\partial i}=0 .
\end{aligned}
$$




$$
\frac{\partial y_{\mathrm{CP}}}{\partial i}>0 \quad \text { and } \quad \frac{\partial y_{\mathrm{MU}}}{\partial i}=0
$$

Since corporate coupon income is ordinary income taxable, equilibrium corporate yields are grossed up to offset increased ordinary income taxation. However, municipal coupon income is tax-exempt.

The change in corporate yields resulting from changes in the capital gains tax rate is given by

$$
\frac{\partial y_{\mathrm{CP}}}{\partial g}=\frac{\partial B_{\mathrm{CP}} / \partial g}{\left(C / y_{\mathrm{CP}}^{2}\right)\left(\exp \left(-y_{\mathrm{CP}} \tau\right)-1\right)-\tau\left(1-C / y_{\mathrm{CP}}\right) \exp \left(-y_{\mathrm{CP}} \tau\right)},
$$

whereas the change in municipal yields due to changes in the capital gains tax rate may be shown to be

$$
\frac{\partial y_{\mathrm{MU}}}{\partial g}=\frac{\partial B_{\mathrm{MU}} / \partial g}{\left(C / y_{\mathrm{MU}}^{2}\right)\left(\exp \left(-y_{\mathrm{MU}} \tau\right)-1\right)-\tau\left(1-C / y_{\mathrm{MU}}\right) \exp \left(-y_{\mathrm{MU}} \tau\right)}
$$

Now, ${ }^{10}$

$$
\operatorname{sgn}\left[\frac{\partial y_{\mathrm{CP}}}{\partial g}\right]=-\operatorname{sgn}\left[\frac{\partial B_{\mathrm{CP}}}{\partial g}\right] \text { and } \operatorname{sgn}\left[\frac{\partial y_{\mathrm{MU}}}{\partial g}\right]=-\operatorname{sgn}\left[\frac{\partial B_{\mathrm{MU}}}{\partial g}\right],
$$

and we may establish that $\partial B_{\mathrm{CP}} / \partial g<0$ and $\partial B_{\mathrm{MU}} / \partial g<0 .{ }^{11}$ Therefore,

$$
\frac{\partial y_{\mathrm{CP}}}{\partial g}>0 \text { and } \frac{\partial y_{\mathrm{MU}}}{\partial g}>0
$$

${ }^{10}$ Here we note that the denominators of $\partial y_{C P} / \partial g$ and $\partial y_{M U} / \partial g$ are also unambiguously negative. This follows from footnote 8 , and noting that the denominator of $\partial y_{\mathrm{CP}} / \partial g$ corresponds to the denominator of $\partial y_{\mathrm{CP}} / \partial i$, while the denominator of $\partial y_{\mathrm{MU}} / \partial \mathrm{g}$ corresponds to the denominator of $\partial y_{\mathrm{MU}} / \partial i$.

${ }^{11}$ Initially consider $\partial B_{\mathrm{CP}}(m) / \partial g=C T(1-g)^{-1} \int_{t}^{m} P(\omega) \mathrm{d} \omega+C T \int_{t}^{m}(\partial P(\omega) / \partial g) \mathrm{d} \omega+\partial P(m) / \partial g$, where we have temporarily suppressed functional dependence. We can express the equilibrium pure discount bond price as $P(\omega)=E_{t} Y(\omega) \exp (-T X(\omega))$, where $X(\omega)=\int_{t}^{\omega} r(s)$ ds, while $Y(\omega)=$ $\exp \left(-1 / 2 \int_{t}^{\omega} \lambda^{2}(r(s), s) \mathrm{d} s+\int_{t}^{\omega} \lambda(r(s), s) \mathrm{d} Z(s)\right)$. Since $X(\omega) \geqq 0$, according to Taylor's theorem we have

$$
\begin{aligned}
& (1 / h)\{Y(\omega) \exp (-(T+h) X(\omega)-Y(\omega) \exp (-T X(\omega))\} \\
& \quad=-X(\omega) Y(\omega) \exp (-T X(\omega))+\left(h X^{2}(\omega) / 2\right) \exp (-(T+\theta h) X(\omega),
\end{aligned}
$$

where $\theta$ is random and $0 \leqq \theta \leqq 1$. For $X(\omega) \geqq 0$, the function $\left(X^{2}(\omega) / 2\right) \exp (-T X(\omega))$ is bounded between zero and some constant $B_{T}$. Therefore, for $h>0$

$$
\begin{aligned}
-\mathrm{E}_{t} X(\omega) Y(\omega) \exp (-T X(\omega)) & \leqq(1 / h)\left\{\mathrm{E}_{t} Y(\omega) \exp (-(T+h) X(\omega))-\mathrm{E}_{t} Y(\omega) \exp (-T X(\omega))\right\} \\
& \leqq-\mathrm{E}_{t} X(\omega) Y(\omega) \exp (-T X(\omega))+h B_{T}
\end{aligned}
$$


Both equilibrium corporate yields and equilibrium municipal yields increase (decrease) with an increasing (decreasing) capital gains tax rate. Intuitively, since both corporate and municipal issues are selling at a discount, an increase in the prevailing capital gains tax rate results in increased taxation of realizable appreciation. Equilibrium yields are grossed up to offset this increased taxation.

Equilibrium yields are also dependent upon the coupon level. The initial characterization of the coupon effect is due to Buse (1970): if the yield-tomaturity of a bond is greater (less) than an average of future nominal spot rates expected to prevail over the maturity of the bond, a positive (negative) coupon effect results. ${ }^{12}$ Intuitively, the coupon effect arises because of a divergence between the holding period yield and yield-to-maturity. To generalize this result within our uncertainty framework with taxation, initially we totally differentiate (8) with respect to $y_{\mathrm{CP}}$ and $C$ :

$$
\begin{aligned}
& \frac{\partial y_{\mathrm{CP}}}{\partial C}=\frac{\left[T \int_{t}^{m} P(r(t), t, \omega) \mathrm{d} \omega-y_{\mathrm{CP}}^{-1}+y_{\mathrm{CP}}^{-1} \exp \left(-y_{\mathrm{CP}} \tau\right)\right]}{\left(C / y_{\mathrm{CP}}^{2}\right)\left(\exp \left(-y_{\mathrm{CP}} \tau\right)-1\right)-\tau\left(1-C / y_{\mathrm{CP}}\right) \exp \left(-y_{\mathrm{CP}} \tau\right)}, \quad \text { and } \\
& \operatorname{sgn}\left[\frac{\partial y_{\mathrm{CP}}}{\partial C}\right]=-\operatorname{sgn}\left[T \int_{t}^{m} P(r(t), t, \omega) \mathrm{d} \omega-y_{\mathrm{CP}}^{-1}+y_{\mathrm{CP}}^{-1} \exp \left(-y_{\mathrm{CP}} \tau\right)\right]
\end{aligned}
$$

For $h<0$, the inequalities are reversed. Letting $h \rightarrow 0$ we obtain $\partial P(\omega) / \partial T=-\mathrm{E}_{t} X(\omega) Y(\omega) \exp$ $(-T X(\omega))$. Then.

$$
\begin{aligned}
\partial B_{C P}(m) / \partial g= & (C T /(1-g)) \int_{t}^{m} \mathrm{E}_{t} Y(\omega) \exp (-T X(\omega)) \mathrm{d} \omega \\
& +(C T /(1-g)) \int_{t}^{m} \mathrm{E}_{\mathrm{t}}-T X(\omega) Y(\omega) \\
& \times \exp (-T X(\omega)) \mathrm{d} \omega-T /(1-g) \mathrm{E}_{t} X(m) Y(m) \exp (-T X(m))
\end{aligned}
$$

Since $\{Y(\omega): \omega \geqq 0\}$ is a martingale, we have

$$
(\partial / \partial m)\left(\partial B_{\mathrm{CP}}(m) / \partial g\right)=(-T /(1-g)) \mathrm{E}_{t}\{(r(m)-C)(1-T X(m))\} Y(m) \exp (-T X(m) .
$$

Notice that (i) $\partial^{2} B_{\mathrm{CP}}(m) / \partial m \partial g \rightarrow-T(1-g)^{-1}(r(t)-C)<0$ as $m \rightarrow t$, since the coupon bond is assumed currently selling at a discount from par; (ii) there exists a unique and finite $m^{*}$, defined by $1-T X\left(m^{*}\right)=0$, for which $\partial^{2} B_{\mathrm{CP}}(m) / \partial m \partial g=0$. Remarks (i) and (ii), together with the observation that $\partial B_{\mathrm{CP}}(m) / \partial g \rightarrow 0$ as $m \rightarrow t$ and $\partial B_{\mathrm{CP}}(m) / \partial g \rightarrow 0$ as $m \rightarrow \infty$, is sufficient to establish that $\partial B_{\mathrm{CP}}(m) / \partial g<0$ for all $m \in(0, \infty)$. A completely analogous argument establishes that $\partial B_{M U}(m) / \partial g<0$ for all $m \in(0, \infty)$.

${ }^{12} \mathrm{~A}$ word of caution is appropriate at this point. Our discussion of the coupon effect concentrates solely on Buse's (1970) characterization. Subsequently, Khang (1975), Schaefer (1977), and Shiller and Modigliani (1979) derived a somewhat stronger specification of the coupon effect based on current rather than expected interest rates. No assumptions regarding uncertainty and reinvestment rates are required. Our analysis of the coupon effect does not pertain to their results. 
or equivalently, ${ }^{13}$

$$
\operatorname{sgn}\left[\frac{\partial y_{\mathrm{CP}}}{\partial C}\right]=-\operatorname{sgn}\left[\exp \left(-y_{\mathrm{CP}} \tau\right)-P(r(t), t, m)\right]
$$

Upon simplification, the appropriate characterization of the coupon effect in the case of a fully taxable coupon bond is

$$
\begin{aligned}
& \frac{\partial y_{\mathrm{CP}} \gtreqless 0, \text { as }}{\partial C} \gtreqless \\
& y_{\mathrm{CP}} \gtreqless-\tau^{-1} \ln \mathrm{E}_{t} \exp \left\{-\int_{t}^{m}\left[\operatorname{Tr}(s)+1 / 2 \lambda^{2}(r(s), s)\right] \mathrm{d} s+\int_{t}^{m} \lambda(r(s), s) \mathrm{d} Z(s)\right\} .
\end{aligned}
$$

An analogous argument in the case of a tax-exempt coupon bond gives

$$
\begin{aligned}
& \frac{\partial y_{\mathrm{MU}}}{\partial C} \gtreqless 0, \text { as } \\
& y_{\mathrm{MU}} \gtreqless-\tau^{-1} \ln \mathrm{E}_{t} \exp \left\{-\int_{t}^{m}\left[\operatorname{Tr}(s)+1 / 2 \lambda^{2}(r(s), s)\right] \mathrm{d} s+\int_{t}^{m} \lambda(r(s), s) \mathrm{d} Z(s)\right\} .
\end{aligned}
$$

Two details should be noted with regard to the coupon effect. First, the impact of coupon level upon equilibrium corporate yields differs from its impact upon equilibrium municipal yields. This result follows from the differential taxation of corporate and municipal issue which ensures that, ceteris paribus, $y_{\mathrm{CP}} \neq y_{\mathrm{MU}}$. Second, if the yield-to-maturity corresponds to the expected holding period yield then a negative coupon effect results. This result is due to uncertainty surrounding the realization of future nominal spot rates of interest. We verify this by temporarily ignoring differential taxation, setting $i=0$ and $g=0$ or equivalently $T=1$, and ceteris paribus, $y_{\mathrm{CP}}=$ $y_{\mathrm{MU}} \equiv y$ since no distinction now exists between corporate and municipal

\footnotetext{
${ }^{13}$ From (8), the the equilibrium corporate yield, $y_{\mathrm{CP}}$; is implicitly defined by
}

$$
C T \int_{t}^{m} P(r(t), t, \omega) \mathrm{d} \omega+P(r(t), t, m)=C y_{\mathrm{CP}}^{-1}+\left(1-C y_{\mathrm{CP}}^{-1}\right) \exp \left(-y_{\mathrm{CP}} \tau\right) .
$$

Rearranging, we have

$$
T \int_{t}^{m} P(r(t), t, \omega) \mathrm{d} \omega-y_{\mathrm{CP}}^{-1}+y_{\mathrm{CP}}^{-1} \exp \left(-y_{\mathrm{CP}} \tau\right)=C^{-1}\left(\exp \left(-y_{\mathrm{CP}} \tau\right)-P(r(t), t, m)\right) .
$$

It follows that

$$
\operatorname{sgn}\left[T \int_{t}^{m} P(r(t), t, \omega) \mathrm{d} \omega-y_{\mathrm{CP}}^{-1}+y_{\mathrm{CP}}^{-1} \exp \left(-y_{\mathrm{CP}} \tau\right)\right]=\operatorname{sgn}\left[\exp \left(-y_{\mathrm{CP}} \tau\right)-P(r(t), t, m)\right] .
$$


issues. The appropriate characterization of the coupon effect becomes

$$
\begin{aligned}
& \frac{\partial y}{\partial C} \gtreqless 0, \text { as } \\
& y \gtreqless-\tau^{-1} \ln E_{t} \exp \left\{-\int_{t}^{m}\left[r(s)+1 / 2 \lambda^{2}(s, r(s))\right] \mathrm{d} s+\int_{t}^{m} \lambda(s, r(s)) \mathrm{d} Z(s)\right\} .
\end{aligned}
$$

Assume that the current yield-to-maturity coincides with the current riskadjusted average of nominal spot rates expected to prevail over the term to maturity of the bond,

$$
y=\tau^{-1} \mathrm{E}_{t}\left\{\int_{t}^{m}\left[r(s)+1 / 2 \lambda^{2}(s, r(s))\right] \mathrm{d} s-\int_{t}^{m} \lambda(s, r(s)) \mathrm{d} Z(s)\right\} .
$$

But by Jensen's Inequality [see Feller (1971, especially pp. 153-154)] we have,

$$
\begin{aligned}
& \tau^{-1} \mathrm{E}_{t}\left\{\int_{t}^{m}\left[r(s)+1 / 2 \lambda^{2}(s, r(s))\right] \mathrm{d} s-\int_{t}^{m} \lambda(s, r(s)) \mathrm{d} Z(s)\right\} \\
& <-\tau^{-1} \ln \mathrm{E}_{t} \exp \left\{-\int_{t}^{m}\left[r(s)+1 / 2 \lambda^{2}(s, r(s))\right] \mathrm{d} s+\int_{t}^{m} \lambda(s, r(s)) \mathrm{d} Z(s)\right\},
\end{aligned}
$$

and a negative coupon effect must result. Intuitively, although yield-tomaturity coincides with expected holding period yield, there exists uncertainty regarding the holding period yield. To diminish the effects of this uncertainty, the prices of bonds with larger coupons are bid up. These bonds have less return in the form of appreciation realized at maturity and greater return in the form of coupon disbursements over the entire term to maturity. Given uncertain reinvestment rates, larger coupon disbursements are to be preferred to a larger lump-sum payment at maturity. Indeed, if the current yield-to-maturity exceeds the current risk-adjusted average of expected nominal spot rates, a negative coupon effect may still obtain simply reflecting this preference for bonds with larger coupons. ${ }^{14}$ The recent empirical analysis of Brennan and Schwartz (1982) consistently documented negative coupon effects, the predominance of which would be expected in a world of uncertainty.

\footnotetext{
${ }^{14}$ These coupon effect results are generalizable to the case where $n$ state variables characterize equilibrium bond prices. Intuitively, our derivation of these results does not depend upon the equilibrium bond prices being a function of a single state variable.
} 
To summarize, this section has examined the impact of alternative tax rates and alternative coupon levels upon equilibrium corporate and municipal yields. We assumed that equilibrium bond prices were characterized by a single state variable, the nominal spot rate of interest, whose dynamics were described by a non-standardized Wiener process. To further investigate the tax structure and coupon structure of interest rates and, in particular, investigate tax-induced biases in the yield curve requires a more specialized characterization of the nominal spot rate process.

\section{Simulation results and the tax-adjusted yield curve}

We now specialize our analysis by assuming nominal spot rate dynamics follow a trend-adjusted version of the Ornstein-Uhlenbeck process,

$$
\mathrm{d} r(t)=k(\mu-r(t)) \mathrm{d} t+\sigma_{r} \mathrm{~d} Z(t)
$$

with $k>0$ and $\sigma_{r}>0$ constants. The instantaneous drift, $k(\mu-r(t))$, implies that the current nominal spot rate reverts elastically to a long-term mean, $\mu>0$, with a speed of adjustment $k>0$. The instantaneous variance, $\sigma_{r}^{2}$, is such that the process fluctuates initially about the path of adjustment and subsequently about the long-term mean continuously and independent of both time and the level of the nominal spot rate. This specification is due to Merton (1971) and Vasicek (1977). The previous analysis of Dobson et al. (1971) supports the empirical validity of this nominal spot rate specification. However, an empirical inadequacy of this specification is that it implies a constant long-term rate of interest, a feature not recently evident in bond markets.

A further property of the trend-adjusted Ornstein-Uhlenbeck specification is that with probability one negative nominal spot rates obtain transiently. We examine the relevance of this implication by considering $\gamma_{0}$, the corresponding mean time required to reach a non-positive interest rate level given an initial nominal spot rate of interest $r_{0}>0$ where

$$
\gamma_{0}=2\left(\frac{\Pi}{\sigma_{r}^{2} \mathrm{k}}\right)^{\frac{1}{2} r_{0}-\mu} \int_{0}^{\mu} \Phi\left\{\left(\frac{\sigma_{r}^{2}}{2 k}\right)^{\frac{1}{2}} x\right\} \exp \left(\frac{k x^{2}}{\sigma_{r}^{2}}\right) \mathrm{d} x
$$

and $\Phi$ is the standardized normal cumulative function. ${ }^{15}$ Langetieg (1980) argues that the trend-adjusted Ornstein-Uhlenbeck process is an adequate representation of nominal spot rate dynamics provided the current nominal spot rate is well above zero. Notice that $\partial \gamma_{0} / \partial r_{0}>0$ and indeed the greater the current nominal spot rate, the greater the mean time required to reach a

\footnotetext{
${ }^{15}$ This result follows from Cox and Miller $\left(1972\right.$, p. 249). Here $\gamma_{0}$ must be evaluated numerically.
} 
non-positive interest rate level. However, $\gamma_{0}$ depends critically on all the parameters of the trend-adjusted Ornstein-Uhlenbeck process. For example, assuming reasonable annualized parameter values of $r_{0}=0.095, \mu=0.056$, $k=0.074$ and $\sigma_{r}=0.007$, the plausibility of these parameter values to be established below, then $\gamma_{0} \simeq 132$ quarters. We emphasize that there do exist reasonable characterizations of the trend-adjusted Ornstein-Uhlenbeck process for which $\gamma_{0}$ is sufficiently large, and hence the possibility of reaching a non-positive interest rate level over any finite term of policy interest is negligible. We then implicitly restrict our attention to these plausible characterizations throughout the subsequent analysis.

To conclude our specification, we characterize the market price of risk. This premium is determined within the economy's underlying equilibrium and is dependent upon investors' preferences, endowments, and available production opportunities. From Vasicek (1977), we assume

$$
\lambda(r(t), t)=\lambda,
$$

a constant independent of time and the prevailing level of the nominal spot rate.

Following Vasicek (1977), the equilibrium price of a capital gains taxable pure discount bond may now be expressed as ${ }^{16}$

$$
\begin{aligned}
P(r(t), t, \omega)= & \exp \left[k^{-1}(1-\exp (-k(\omega-t))(\eta-\operatorname{Tr}(t))\right. \\
& \left.-(\omega-t) \eta-\left(\sigma_{r}^{2} / 4 k^{3}\right)(1-\exp (-k(\omega-t)))^{2}\right],
\end{aligned}
$$

where

$$
\eta=\mu-\left(\sigma_{r} / k\right) \lambda-1 / 2\left(\sigma_{r}^{2} / k^{2}\right) .
$$

By expression (6), the equilibrium price of a default-free fully taxable corporate bond may be explicitly written as

$$
\begin{aligned}
B_{\mathrm{CP}}(r(t), t, m)= & C r(t)^{-1}+[1+C T((\eta-T r(t)) \exp (-k \tau)-\eta \\
& \left.\left.-\left(\sigma_{r}^{2} / k^{2}\right)(1-\exp (-k \tau)) \exp (-k \tau)\right)^{-1}\right] \\
& \times \exp \left[k^{-1}(1-\exp (-k \tau))(\eta-\operatorname{Tr}(t))-\tau \eta\right. \\
& \left.-\left(\sigma_{r}^{2} / 4 k^{3}\right)(1-\exp (-k \tau))\right] .
\end{aligned}
$$

\footnotetext{
${ }^{16}$ Vasicek (1977) examined the equilibrium pricing of pure discount bonds in the absence of differential taxation. Vasicek's equilibrium pure discount bond price [see Vasicek (1977 especially p. 185, eq. (27))] differs from our solution in only that the role of $r(t)$ is now replaced by $\operatorname{Tr}(t)$ where $T=(1-i) /(1-g)$, reflecting the ordinary income taxation of the single state variable and the capital gains taxation of the pure discount bond.
} 
Alternatively, by expression (7), the equilibrium price of a default-free taxexempt municipal bond may be expressed as

$$
\begin{aligned}
B_{\mathrm{MU}}(r(t), t, m)= & C((1-i) r(t))^{-1} \\
& +\left[1+C(1-g)^{-1}((\eta-\operatorname{Tr}(t)) \exp (-k \tau)-\eta\right. \\
& \left.\left.-\left(\sigma_{r}^{2} / k^{2}\right)(1-\exp (-k \tau)) \exp (-k \tau)\right)^{-1}\right] \\
& \times \exp \left[k^{-1}(1-\exp (-k \tau))(\eta-\operatorname{Tr}(t))-\tau \eta\right. \\
& \left.-\left(\sigma_{r}^{2} / 4 k^{3}\right)(1-\exp (-k \tau))^{-1}\right] .
\end{aligned}
$$

Notice that as $\sigma_{r} \rightarrow 0^{+}$, the Ornstein-Uhlenbeck nominal spot rate process becomes deterministic. Further, as $k \rightarrow 0^{+}$, the speed of adjustment is such that the prevailing nominal spot rate never deviates from the long-term mean. Intuitively, given these restrictions investors possess a flat and nonstochastic expectation of future nominal spot rates,

$$
r(t)=\mu, \quad \text { all } t>0 .
$$

Applying these restrictions to expressions (10) and (11), the equilibrium price of a default-free fully taxable corporate bond becomes

$$
B_{\mathrm{CP}}(r(t), t, m)=C r(t)^{-1}+\left[1-C r(t)^{-1}\right] \exp (-\operatorname{Tr}(t) \tau),
$$

while the equilibrium price of a default-free tax-exempt municipal bond becomes

$$
B_{\mathrm{MU}}(r(t), t, m)=C((1-i) r(t))^{-1}+\left[1-C((1-i) r(t))^{-1}\right] \exp (-\operatorname{Tr}(t) \tau) .
$$

However, these are precisely the equilibrium prices of a default-free corporate bond and a default-free municipal bond derived by Shiller and Modigliani (1979). This intuitively follows since Shiller and Modigliani (1979) assume a flat and non-stochastic expectation of future nominal spot rates.

We have explicitly characterized equilibrium corporate and municipal bond prices by specializing nominal spot rate dynamics and the market price of risk. Within this particular framework, we now proceed to investigate tax induced biases in the yield curve. We employ U.S. Treasury bill data over the period 1959.I to 1978.IV to specify empirically the trend-adjusted OrnsteinUhlenbeck nominal spot rate process and the prevailing market price of risk. Consequently, equilibrium coupon bond prices may be simulated and the tax induced biases in the resultant yield curves become evident. Further insight 
into the consequences of differential taxation upon the tax and coupon structure of interest rates is also provided.

Given that interest rate data are available only at discrete points in time, the discrete-time version of the trend-adjusted Ornstein-Uhlenbeck process is estimated,

$$
\Delta r(t)=k(\mu-r(t-1))+\varepsilon(t), \quad t=1,2, \ldots, M,
$$

or equivalently,

$$
r(t)=k \mu+(1-k) r(t-1)+\varepsilon(t), \quad t=1,2, \ldots, M,
$$

where $M$ denotes the number of observations with

$$
\begin{array}{ll}
\mathrm{E} \varepsilon(t)=0, & \text { all } t, \\
\mathrm{E} \varepsilon^{2}(t)=\sigma_{r}^{2}, & \text { all } t, \\
\mathrm{E} \varepsilon(s) \varepsilon(t)=0, & \text { all } s \neq t .
\end{array}
$$

Employing quarterly observations of the three-month U.S. Treasury bill rate over the period 1959.I to 1978.IV and ordinary least squares, the results in table 1 were obtained.

Table 1

\begin{tabular}{lcccc}
\hline$k \mu$ & $1-k$ & $s$ & $h$ & $\bar{R}^{2}$ \\
\hline 0.00413 & 0.926 & 0.00657 & 0.8357 & 0.8265 \\
$(0.0024)$ & $(0.038)$ & & & \\
\hline
\end{tabular}

An estimate of the long-term mean interest rate level is $\hat{\mu}=0.0558$, and the estimated speed of adjustment factor is $\hat{k}=0.074$. The Durbin (1970) $h$ statistic indicates no evidence against the hypothesis of zero autocorrelation at the 5 percent significance level. An estimate of the standard deviation of the trendadjusted Ornstein-Uhlenbeck process is provided by $s \equiv \hat{\sigma}_{r}=0.00657$.

The market price of risk gives the additional expected bond rate of return commensurate with bearing an additional unit of risk as measured by the standard deviation of the bond rate of return. In equilibrium, the market price of risk is independent of term to maturity. Accordingly, quarterly observations of three-month and six-month U.S. Treasury bill rates over the period 1960.I to 1978.IV were employed to construct a time series measuring the excess three-month holding period return to six-month U.S. Treasury bills. An estimate of the market price of risk is given by the ratio of the mean 
of the constructed series to its standard deviation. The former provides a measure of the expected excess rate of return to six-month U.S. Treasury bills while the latter provides a measure of the risk of that rate of return. The mean is estimated to be 0.005 , with an estimated variance of $0.64 \times 10^{-4}$; as a result we have $\hat{\lambda}=-0.625$.

This estimate of the market price of risk is broadly consistent with Brennan and Schwartz's (1982) recent estimates employing U.S. data. To complete our specification, we note that as of the last week of 1978.IV, $r(t)=$ 0.09498 . We now turn to our simulation results which further examine the impact of coupon, tax, and term to maturity upon equilibrium yields, given this particular empirical characterization of the economy's underlying equilibrium.

In fig. 1 we present simulated equilibrium yield curves assuming a constant coupon level of $C=0.04$, an ordinary income tax rate of $i=0.40$, and a capital gains tax rate of $g=0.16$. In comparison with the resultant equilibrium yield curve derived in the absence of taxation, tax induced biases in equilibrium corporate and municipal yield curves become apparent. For this particular specification of prevailing tax rates and coupon level, the taxation of corporate issues exerts a downward bias on the corporate yield curve, the bias diminishing with increasing term to maturity. This result follows since with increasing term to maturity, a discounted corporate bond's capital gains taxable rate of appreciation diminishes and so its tax advantage diminishes. The taxation of municipal issues for this particular specification of prevailing tax rates and coupon level is seen to impart a uniform downward bias on the municipal yield curve. Coupons on municipal bonds are exempt from ordinary income taxation and the observed bias is explained by noting that this tax advantage is independent of term to maturity.

We further investigate these tax effects given our empirical characterization of the economy's underlying equilibrium in fig. 2. There equilibrium cor-

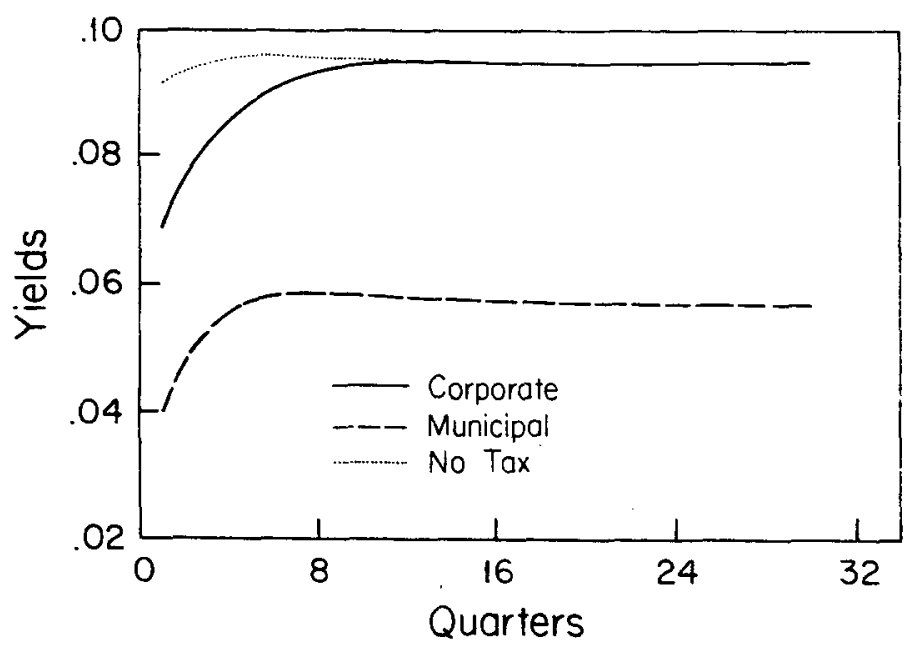

Fig. 1 

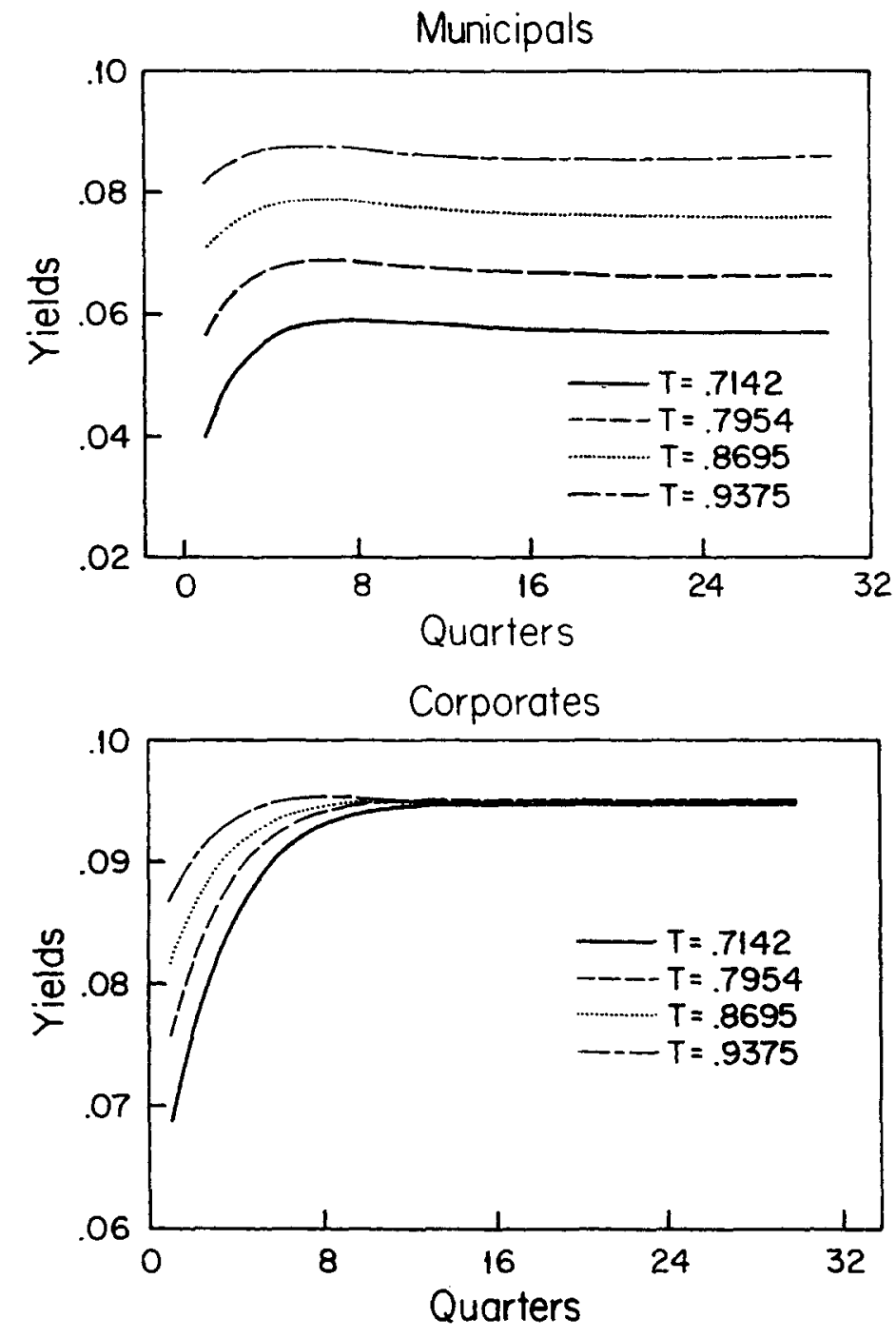

Fig. 2

porate and municipal yield curves assuming a constant coupon of $C=0.04$ but now corresponding to both varying capital gains and ordinary income tax rates are exhibited. We assume $g=0.4 i$ and by increasing $i$ it follows that $g$ increases and $T=(1-i)(1-g)^{-1}$ necessarily decreases. ${ }^{17}$ Lower values of $T$ then index higher prevailing capital gains and ordinary income tax rates. As capital gains and ordinary income tax rates increase, the previously documented bias in the short-term end of the corporate yield curve is increased. With higher prevailing tax rates and a constant coupon level, the tax advantage of short-term discounted corporate bonds is further enhanced. By contrast, the municipal yield curve is displaced further downward with increased capital gains and ordinary income taxation. Since coupons on

${ }^{17}$ Now $T=(1-i)(1-0.4 i)^{-1}$ and $\mathrm{d} T / \mathrm{d} i=(T-1)(1-0.4 i)^{-1}<0$. 
municipal bonds are not taxable, by increasing prevailing tax rates the tax advantage of municipal bonds increases independent of term to maturity.

Finally, fig. 3 examines how these tax induced biases in the yield curve vary with coupon level: recall, equilibrium yields are not independent of coupon level. As before, we assume an ordinary income tax rate of $i=0.40$ and a capital gains tax rate of $g=0.16$, but now present equilibrium corporate and municipal yield curves corresponding to coupon levels of $C=0.01$, $0.02,0.03$, and 0.04 . Given the prevailing capital gains and ordinary income tax rates, changes in coupon level have an indiscernable effect upon corporate yields. However, a systematic municipal coupon effect is evident. Lowering the coupon level imparts an upward bias in the municipal yield curve, and this bias diminishes with increasing term to maturity. To explain the systematic bias, we note that realized appreciation is the only taxable component of a discounted municipal bond's return. Lowering the coupon level
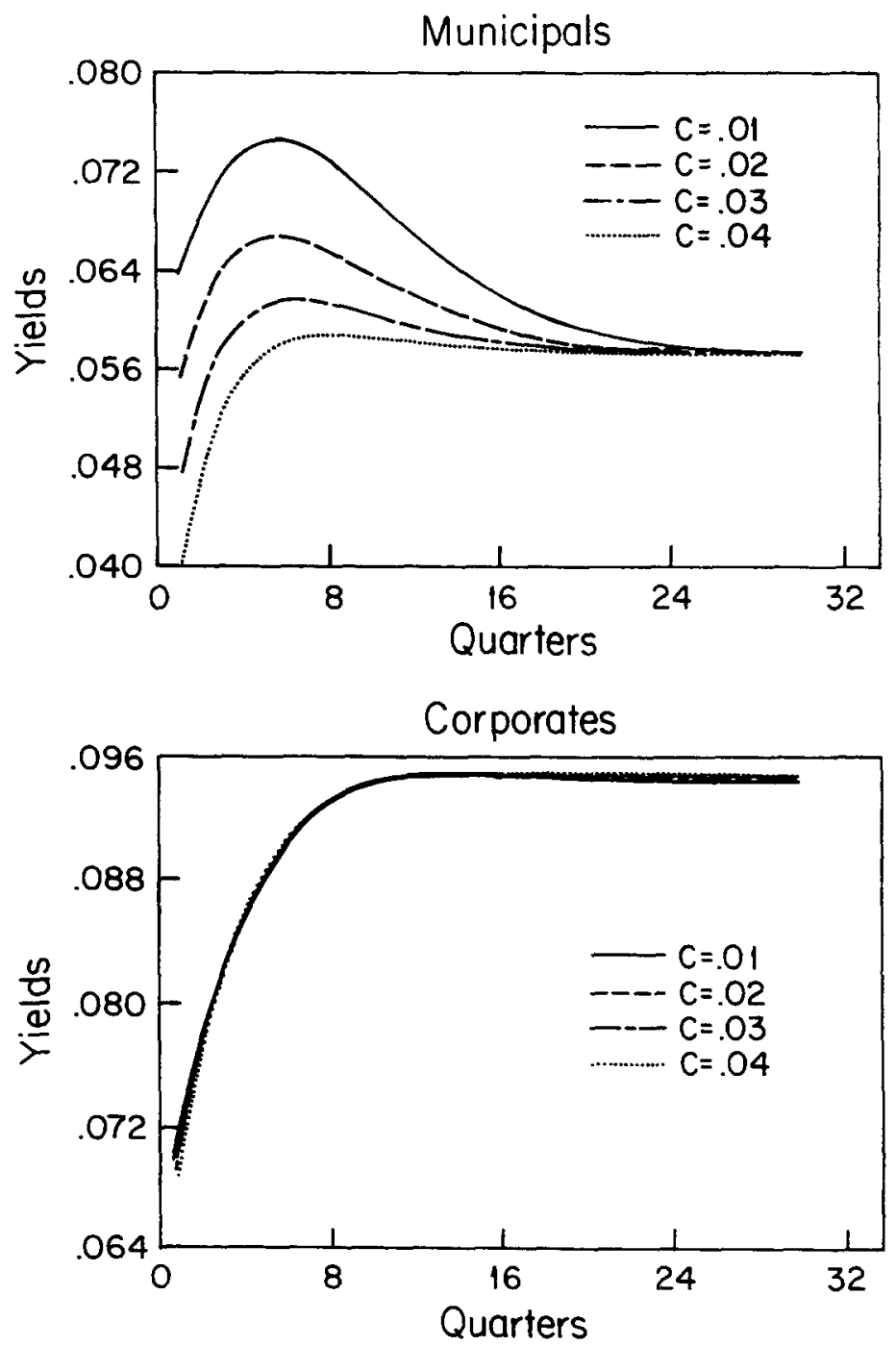

Fig. 3 
deepens the municipal bond's discount from par, consequently increasing the capital gains taxable rate of appreciation. Equilibrium municipal yields then increase with lower coupon levels to offset this tax disadvantage. Since the rate of appreciation diminishes with increasing term to maturity, it follows that a discounted municipal bond's capital gains tax liability diminishes with increasing term to maturity.

Our simulation results have explored the impact of differential taxation upon the equilibrium yield curve. For the parameter values assumed, this analysis indicates that taxation substantially yet systematically affects both equilibrium municipal and corporate yield curves.

\section{Conclusions}

This paper has explored the impact of differential taxation upon the equilibrium structure of interest rates. The analysis was conducted at three levels of generality. Assuming that the underlying state variables were generated by a multidimensional non-standardized Wiener process, equilibrium coupon bond valuation relationships given differential taxation were established. In particular, we considered the differential taxation of realized appreciation and coupon income, and the differential taxation of corporate and municipal coupon income. In order to investigate the impact of both varying tax rates and varying coupon levels upon equilibrium corporate and municipal yields, the analysis was subsequently simplified by positing a single state variable, the nominal spot rate of interest. We then characterized the capital gains and ordinary income tax structure of interest rates for corporate and municipal issues, and examined both corporate and municipal coupon effects. Finally, the analysis was specialized by assuming a specific nominal spot rate process, the trend-adjusted Ornstein-Uhlenbeck process, with particular parameters estimated on the basis of U.S. Treasury bill data. The resultant simulation studies allowed us to indicate tax induced biases in equilibrium corporate and municipal yield curves.

Our analysis is distinct from earlier research in that bond market uncertainty is explicitly incorporated into equilibrium bond valuation relationships. Formal cognizance is given to the fact that the imposition of taxation reduces not only the expected return to an uncertain investment but also the corresponding risk. We provide then a parsimonious framework to evaluate the effects of taxation policy changes upon the equilibrium structure of interest rates.

\section{References}

Ananthanarayanan, A.L. and Eduardo S. Schwartz, 1980, Retractable and extendible bonds: The Canadian experience, Journal of Finance 35, 31-47.

Brennan, Michael J. and Eduardo S. Schwartz, 1977, Savings bonds, retractable bonds, and callable bonds, Journal of Financial Economics 5, 67-88. 
Brennan, Michael J. and Eduardo S. Schwartz, 1982, An equilibrium model of bond pricing and a test of market efficiency, Journal of Financial and Quantitative Analysis 17, 301-329.

Buse, A., 1970, Expectations, prices, coupons and yields, Journal of Finance 25, 809-818.

Buse, A., 1975, Reply, Journal of Finance 30, 1141-1142.

Constantinides, George M., 1983, Capital market equilibrium with personal tax, Econometrica $51,611-636$.

Constantinides, George M. and Jonathan E. Ingersoll, Jr., 1982, Optimal bond trading with personal taxes: Implications for bond prices and estimated tax brackets and yield curves, CRSP working paper no. 70 (Graduate School of Business, University of Chicago, Chicago, IL).

Cox, D.R. and H.D. Miller, 1972, The theory of stochastic processes (Chapman and Hall, London).

Dobson, Steven W., Richard C. Sutch and David E. Vanderford, 1976, An evaluation of alternative empirical models of the term structure of interest rates, Journal of Finance 31, 1035-1065.

Domar, Evsey D. and R.A. Musgrave, 1944, Proportional income taxation and risk-taking, Quarterly Journal of Economics 58, 387-422.

Dothan, Uri, 1978, On the term structure of interest rates, Journal of Financial Economics 6, $59-70$.

Durbin, J., 1970, Testing for serial correlation in least squares regression when some of the regressors are lagged dependent variables, Econometrica 38, 410-421.

Feller, W., 1971, An introduction to probability theory and its applications, Vol. II (Wiley, New York).

Friedman, Avner, 1964, Partial differential equations of parabolic types (Prentice-Hall, Englewood Cliffs, NJ).

Khang, Chulsoon, 1975, Expectations, prices, coupons and yields: Comment, Journal of Finance $30,1137-1140$.

Langetieg, Terrence C., 1980, A multivariate model of the term structure, Journal of Finance 35, 71-97.

McCulloch, J. Huston, 1975, The tax-adjusted yield curve, Journal of Finance 30, 811-830.

Merton, Robert C., 1971, Optimum consumption and portfolio rules in a continuous-time model, Journal of Economic Theory, 3, 373-413.

Merton, Robert C., 1973, The theory of rational option pricing, Bell Journal of Economics and Management Science 4, 141-183.

Robichek, Alexander A. and W. David Niebuhr, 1970, Tax induced bias in reporting treasury yields, Journal of Finance 25, 1081-1090.

Schaefer, Stephen M., 1977, The problem with redemption yields, Financial Analysts Journal 33, $59-67$.

Schaefer, Stephen M., 1981, Measuring a tax-specific term structure of interest rates in the market for British government securities, Economic Journal, 415-438.

Schaefer, Stephen M., 1982, Taxes and security market equilibrium, in: Financial economics: Essays in honor of Paul Cootner (Prentice-Hall, Englewood Cliffs, NJ).

Shiller, Robert J. and Franco Modigliani, 1979, Coupon and tax effects on new and seasoned bond yields and the measurement of the cost of 'debt capital, Journal of Financial Economics $7,297-318$.

Vasicek, Oldrich, 1977, An equilibrium characterization of the term structure, Journal of Financial Economics 5, 177-188. 